\title{
La contaminación de la confianza. Los árbitros tóxicos y la deliberación arbitral en Latinoamérica
}

\author{
José María de la Jara Plaza* \\ Julio Olórtegui Huamán** \\ Recibido/Received: $31 / 01 / 2017$ \\ Aceptado/Accepted: 03/02/2017
}

SUMARIO: 1. El arbitraje y la paradoja de la confianza. 2. Reglas de juego de la deliberación. 3. Deliberación y árbitros tóxicos. 3.1 El Árbitro Salomónico. 3.2 El Árbitro Procesalosaurio. 3.3 El Árbitro Justiciero. 3.4 El Árbitro Fantasma. 3.5 El Árbitro Delivery. 3.6 El Árbitro Blandengue. 3.7 El Árbitro Egocéntrico. 3.8 El Árbitro Informante. 3.9 El Ârbitro Kamikaze. 3.10 Los Árbitros Gangsters. 4. Siete consejos para promover una deliberación sana. 5. Palabras finales.

PALABRAS CLAVES: Deliberación, Pacto de las artes, Imparcialidad, Independencia, Sesgos Cognitivos, Psicología, Arbitraje Internacional.

KEYWORDS: Deliberation, pact of arts, imparciality, independence, cognitive disortions, psychology, international arbitration.

* Asociado de Bullard Falla Ezcurra +. Profesor de Análisis Psicológico del Derecho en la Universidad del Pacífico. Director Ejecutivo y Director de la Comisión de Persuasión y Sistemas de Justicia de PsychoLAWgy.

** Asociado de Bullard Falla Ezcurra +. Investigador de Lex Arbitri. Analista de la Comisión de Psicología del Consumidor de PsychoLAWgy.

Los autores desean agradecer a Francisco González de Cossío por sus amables y agudos comentarios. El presente artículo pretende continuar su esfuerzo por describir a quienes llama "árbitros pícaros". F. González de Cossío, Arbitraje, Editorial Porrúa, 2004. p. 556.

J.M. de la Jara Plaza y J. Olórtegui Huamán, "La contaminación de la confianza. Los árbitros tóxicos y la deliberación arbitral en Latinamérica”, Revista Ecuatoriana de Arbitraje, No. 8, 2016. 
RESUMEN: La deliberación del tribunal arbitral es como la caja negra de un avión. Protegida por la confidencialidad, es difícil que las partes conozcan su contenido. Solo los árbitros, tripulantes del proceso, saben realmente cómo se desarrollan las deliberaciones. En los últimos años se han ventilado distintas prácticas que contaminan el arbitraje, especialmente durante la etapa de deliberación. El presente ensayo busca desenmascarar dichas prácticas tóxicas, que infectan la confianza depositada por las partes y la predictibilidad del arbitraje. En esa línea, los autores han construido diez perfiles de árbitros tóxicos en base a su experiencia y a la jurisprudencia internacional, han realizado una encuesta de percepción a ciento cincuenta y ocho practicantes en Latinoamérica y, en base a lo anterior, brindan herramientas concretas para lidiar con cada uno de aquellos durante las deliberaciones.

ABSTRACT: the process of deliberation of an arbitral tribunal is similar to a black box of an airplane: it is fully protected of confidentiality, and its content remains private for the ones that are involved in this process: arbitrators; in contrast, parties will never know the development of this process. Lately, several practices pollute the arbitration, especially, the deliberation stage. This article aims to determine toxic practices that affects the confidence placed by the parties and makes arbitration predictable. In this matter, the authors have created ten toxic arbitrator profiles based on their experience and international case law; moreover, a survey has been made to one hundred fifty-eight practitioners in Latin America, which provides the necessary tools to deal with every profile developed during deliberation.

\section{El arbitraje Y LA PARAdojA DE LA CONFIANZA}

El arbitraje es una criatura del consenso. Como tal, se origina en la voluntad de las partes de separarse de la justicia ordinaria, 
moldear el proceso a sus expectativas y escoger quiénes decidirán la disputa.

Las partes depositan su confianza en tomadores de decisiones imparciales e independientes para que decidan de manera colegiada la controversia. Sin embargo, dicha designación puede ser irresponsable y derivar en el nombramiento de un árbitro que no cumple con las cualificaciones, al carecer de tiempo, conocimientos, formación, experiencia o habilidades para administrar un proceso.

Peor aún, en ciertas ocasiones la voluntad de una de las partes también podría estar contaminada, intentando evitar un proceso limpio y célere. En cambio, persigue controlar el resultado a través de un árbitro elegido para asegurárselo.

Los árbitros tóxicos ${ }^{1}$ contaminan la voluntad de las partes, intoxican las deliberaciones e infectan la validez del laudo. Como comenta BASSLER ${ }^{2}$, incluso se han descubierto casos donde una de las partes pagó los "servicios" de uno de los árbitros contratándole una trabajadora sexual.

Ahora, a simple vista los árbitros tóxicos pueden parecer inofensivos. No son brutos. Como indica BERNARDINI, éstos muestran su verdadera cara durante las deliberaciones para decidir el sentido del laudo ${ }^{3}$. Ahí revelan si son realmente independientes e imparciales o si, más bien, bloquearán la participación de un miembro del tribunal, desaparecerán de las discusiones, sembrarán una anulación, o ejecutarán alguna otra práctica venenosa.

1. En este artículo nos referiremos como "árbitros tóxicos" a la categoría general de árbitros que imponen dificultades en la deliberación. En otras palabras, tanto los árbitros patológicos (que no están calificados para cumplir con el encargo) como los árbitros encamisetados (que no son imparciales ni independientes) forman parte de un grupo más grande, conocido como árbitros tóxicos.

2. W. BAssler, "An Essay on the Challenges to Collegiality", en E. Berger y M. SCheneider, Inside the Black Box. How Arbitral Tribunals Operate and Reach Their Decisions, Association Suisse de 1'Arbitrage and Jurist, 2014, p. 112.

3. P. Bernardini, "Organisation of deliberations" en E. Berger y M. Scheneider (Eds.), Inside the Black Box. How Arbitral Tribunals Operate and Reach Their Decisions, Association Suisse de 1'Arbitrage and Jurist, 2014, p. 16. 
La contaminación de la confianza.

Los árbitros tóxicos y la deliberación arbitral en Latinoamérica

Aprender a deliberar depende de la experiencia pero esta tarda en llegar. Por ello, este ensayo busca acelerar ese aprendizaje que se adquiere en la cancha, compartiendo distintas experiencias en el manejo de las deliberaciones tóxicas. El objetivo es guiar a los actuales y futuros árbitros, de tal modo que cuenten con las herramientas adecuadas para proteger el laudo y la voluntad de las partes.

Entonces, primero explicaremos las reglas de juego de la deliberación; luego, nos centraremos en la descripción de diez perfiles de árbitros tóxicos, su impacto en las deliberaciones y distintas estrategias para combatirlos; $y$, finalmente, resumiremos siete consejos para organizar un procedimiento de deliberación que privilegie el principio de colegialidad.

\section{REgLAS DE JUEGO DE LA DELIBERACIÓN}

La deliberación constituye un esfuerzo conjunto para identificar los asuntos relevantes e intercambiar argumentos, ideas y reflexiones que permitan sopesar las distintas opciones a disposición del tribunal ${ }^{4}$, como decidir si conceder una medida cautelar, obligar a una de las partes a exhibir un documento o resolver la controversia a través del laudo.

A nuestro entender, el procedimiento deliberativo está moldeado a partir del respeto al principio de colegialidad. En ese sentido, todas las reglas de la deliberación deben ser interpretadas de tal manera que permitan garantizar la obligación de los árbitros de participar o al menos tener la oportunidad de expresar su opinión para la formación del laudo.

Desde dicha perspectiva, el objetivo de la deliberación no debe ser llegar a un consenso ${ }^{5}$. Tal como indican SunSTEIN y HASTIE, la

4. B. Berger, "Rights and Obligations of Arbitrators in the Deliberations", ASA Bulletin, Vol. 31(2), 2013, p. 246.

5. J. De la JARA y J. OlóRTEGUI, ¿Tres cabezas piensan mejor que una? La psicología de la deliberación y el rol del Presidente del Tribunal Arbitral, «https://goo.gl/26Z4zU». 
meta es incentivar a los miembros del grupo compartan la mayor cantidad de información posible ${ }^{6}$. Ello permite que el mayor costo del arbitraje se traduzca en un análisis más profundo y una decisión más sustentada, lo cual no tendría por qué estar supeditado a una decisión unánime ${ }^{7}$.

Asimismo, el principio de colegialidad determina que la forma del procedimiento deliberativo sea flexible; ésta debe adaptarse a los árbitros y no al revés. Si bien lo más común es que los árbitros discutan en una reunión presencial, la práctica internacional también acoge deliberaciones por correo electrónico, teléfono o video conferencias. Lo que realmente importan es que, más allá de la forma, cada uno de los árbitros tenga la oportunidad de expresar su opinión.

Vale destacar además que los árbitros deben respetar el secreto de las deliberaciones. Éste implica que están impedidos de revelar lo discutido por el tribunal, salvo contadas excepciones ${ }^{8}$. La confidencialidad es un candado para proteger lo discutido por los árbitros y permitir intercambiar opiniones de manera libre, en respeto al principio de colegialidad.

Sin perjuicio de estas reglas, el contenido y resultado de la deliberación finalmente va a depender de quiénes compongan el tribunal arbitral. Como señala WILLIAM FOSTER, la calidad nunca es un accidente; siempre es el resultado de una intención profunda, un esfuerzo sincero, una dirección inteligente y una ejecución hábil. En ese sentido, la ejecución hábil de una intención contaminada, un esfuerzo calculador y una dirección viciada modificarán el contenido y objetivo de la deliberación.

Atendiendo a lo anterior, a continuación profundizaremos en las soluciones específicas para enfrentar a los diez tipos de árbitros tóxicos que hemos identificado.

6. C. Sunstein y R. Hastie, "Wiser: Getting Beyond Groupthink to Make Groups Smarter", Harvard Business Review Press, 2015, p. 4.

7. J. De la Jara y J. Olórtegui, N. 5.

8. J. WAINCYMER, Procedure and Evidence in International Arbitration, Wolters Kluwer Law \& Business, 2012, p. 1297. Asimismo véase, Himpurna California Energy Ltd. c. Republic of Indonesia, 26/11/1999. 


\section{DELIBERACIÓN Y ÁRBITROS TÓXICOS}

La deliberación es el momento cumbre del arbitraje. Ahí los árbitros se muestran como verdaderamente son. La gran mayoría son trabajadores, estudian el detalle del expediente, se ofrecen a ahondar en determinado problema jurídico, discuten de manera empática e intentan colaborar para arribar a una decisión adecuada.

Los árbitros tóxicos también se sacan las máscaras y muestran sus verdaderas intenciones durante las deliberaciones. Se ausentan, filtran información a la parte que los designó, dinamitan el proceso creando una causal de anulación de laudo, entre otros.

Por ello, hemos creado diez perfiles de árbitros tóxicos y realizado una encuesta de percepción que ha sido respondida por 158 practicantes del arbitraje en Latinoamérica. Ello nos permite advertir al lector sobre las prácticas que contaminan el procedimiento de deliberación, analizar la jurisprudencia aplicable y, especialmente, discutir distintas estrategias para sobrellevar una deliberación tóxica. Estos diez perfiles están separados de la siguiente manera:

\section{Tabla 1 - Perfil de Árbitros Tóxicos}

Fuente: Elaboración propia

\begin{tabular}{|c|l|l|}
\hline Perfil & \multicolumn{1}{|c|}{ Explicación del perfil } & \multicolumn{1}{|c|}{ Fuente relevante } \\
\hline Salomónico & $\begin{array}{l}\text { En vez de invertir tiempo } \\
\text { en el análisis de la contro- } \\
\text { versia, prefiere otorgar a } \\
\text { cada parte la mitad de lo } \\
\text { que pidió ("partir al bebé } \\
\text { por la mitad") }\end{array}$ & $\begin{array}{l}\text { C. DRAHOZAL, "Busting Arbitra- } \\
\text { tiew, ph. 673-674. A. WeBER, et. al, } \\
\text { Baby" Myth in International Arbi- } \\
\text { tration", Journal of International Ar- } \\
\text { bitration, Vol. 31(6), pp. 719-734. }\end{array}$ \\
\hline Procesalosaurio & $\begin{array}{l}\text { Extremadamente forma- } \\
\text { lista; solo quiere deliberar } \\
\text { cara-a-cara }\end{array}$ & $\begin{array}{l}\text { Austria No. 16 D S.A. c. W } \\
\text { GmbH., 26/04/2006. } \\
\text { Tribunal Federal Suizo. Sefri c. } \\
\text { Komgrap del 23/10/1985. }\end{array}$ \\
\hline
\end{tabular}




\begin{tabular}{|c|c|c|}
\hline Justiciero & $\begin{array}{l}\text { Es idealista. Extiende pla- } \\
\text { zos, reabre incidentes y } \\
\text { llama a terceros para arri- } \\
\text { bar a llegar a la Verdad } \\
\text { (con mayúsculas) }\end{array}$ & $\begin{array}{l}\text { Corte de Apelaciones del Quinto } \\
\text { Circuito de los Estados Unidos. } \\
\text { Totem Marine Tug E Barge, Inc. c. } \\
\text { North American Towing, Inc., } \\
\text { 1979, } 607 \text { F.2d 649-651. } \\
\text { Corte de Apelaciones del Tercer } \\
\text { Circuito de los Estados Unidos, } \\
\text { PMA Capital Inc. Co. c. Platinium } \\
\text { Underwriters Bermuda Ltd., } 400 \text { F. } \\
\text { Appx. 2010, p. } 654 .\end{array}$ \\
\hline Fantasma & $\begin{array}{l}\text { Desaparece de las delibera- } \\
\text { ciones }\end{array}$ & $\begin{array}{l}\text { Corte de Apelaciones de Beirut, } \\
\text { Decisión No. } 718 / 2011,03 / 05 / 11 . \\
\text { Caso similar pero en el cual no esta- } \\
\text { mos frente a uno de estos árbitros: } \\
\text { Alta Corte Popular de China, Pro- } \\
\text { vincia de Fujian, First Investment } \\
\text { Corp. c. Fujian Mawei Shipbuilding, } \\
\text { Tld. et al., 12/10/2007 y Suprema } \\
\text { Corte Popular, 27/02/2008. }\end{array}$ \\
\hline Delivery & $\begin{array}{l}\text { Delega todo el trabajo al se- } \\
\text { cretario }\end{array}$ & $\begin{array}{l}\text { UNCITRAL, Yukos Universal Lim- } \\
\text { ited c. The Russian Federation, PCA } \\
\text { Case No. AA 227. High Court of } \\
\text { England and Wales, Queen's } \\
\text { Bench Division, Sonatrach c. Sta- } \\
\text { toil Natural Gas LLC, } 2014 \text { EWHC } \\
875 .\end{array}$ \\
\hline Blandengue & $\begin{array}{l}\text { No tiene carácter y teme } \\
\text { discutir con sus co-árbitros }\end{array}$ & $\begin{array}{l}\text { Corte de Apelaciones de Beirut, } \\
\text { Decisión No. 718/2011, 23/05/11. }\end{array}$ \\
\hline $\begin{array}{c}\text { Egocéntrico } \\
\text { (Super-litigante, Bully) }\end{array}$ & $\begin{array}{l}\text { Quiere ser el centro de } \\
\text { atención }\end{array}$ & $\begin{array}{l}\text { Véase, D. Richmond, "Bullies on } \\
\text { the Bench". Louisiana Law Review, } \\
\text { Vol. 72(2), 2012, pp. 325-327. }\end{array}$ \\
\hline Informante & $\begin{array}{l}\text { Filtra información a la parte } \\
\text { que lo designó }\end{array}$ & $\begin{array}{l}\text { Croacia c. Eslovenia ("Escándalo } \\
\text { Sekolec"). } \\
\text { Véase, K. BöcKSTIEGEL, Chapter 4: } \\
\text { The Boxed Eagle and Catches at } \\
\text { Hearings and Deliberations. Cita- } \\
\text { do en Stories from the Hearing } \\
\text { Room: Experience from Arbitral } \\
\text { Practice (Essays in Honour of M. } \\
\text { E. SCHNEIDER). BAIZEAU, DOMITILLE } \\
\text { y B. EHLE (Eds.), The Hague: } \\
\text { Wolters Kluwer Law \& Business, } \\
2015, \text { p. } 28 \text {. }\end{array}$ \\
\hline
\end{tabular}


La contaminación de la confianza.

Los árbitros tóxicos y la deliberación arbitral en Latinoamérica

\begin{tabular}{|l|l|l|}
\hline Kamikaze & $\begin{array}{l}\text { Se sacrifica y siembra una } \\
\text { "bomba" para que el laudo } \\
\text { sea anulado }\end{array}$ & $\begin{array}{l}\text { Republic of Colombia c. Cauca } \\
\text { Company. }\end{array}$ \\
\hline Gangster & $\begin{array}{l}\text { Se unen para disfrazar al } \\
\text { laudo de validez; garanti- } \\
\text { zan resultados al cliente } \\
\text { que los contrate }\end{array}$ & $\begin{array}{l}\text { Audiencia Provincial de Madrid, } \\
\text { tudio 2000, S.A. (Sección Vigési- } \\
\text { Mutual Insurance Co., 1990, 523, } \\
\text { párr. 541 y, Corte Suprema Popu- } \\
\text { lar de la República Popular de } \\
\text { China, Guangying Garment c. Eura- } \\
\text { sia, 2008. }\end{array}$ \\
\hline
\end{tabular}

A continuación entraremos en una zona contaminada. Vamos a abrir "la caja negra" y entrar al cerebro de los diez tipos de árbitros que más afectan al arbitraje. Es un ambiente tóxico. Lo invitamos a proceder con cautela.

\subsection{El Árbitro Salomónico}

Seinfeld es reconocida como una de las mejores series de los 90's. En uno de los capítulos, Elaine Benes, interpretada por Julia Louis-Dreyfus, promete que regalaría la bicicleta que acababa de comprar a quien pudiera aliviar su dolor de cuello. Inmediatamente, el avispado Kramer se dirige hacia ella y con un rápido giro de cuello le alivia el dolor. "Mándame la bicicleta cuando quieras", sentencia Kramer.

Esta situación genera un conflicto entre Kramer y Elaine, quien no estaba dispuesta a entregar su nueva bicicleta por una promesa que supuestamente no era seria. Por ello, ambos amigos deciden someter su disputa a su vecino Newman. Después de escucharlos, el improvisado juez decide cortar la bicicleta a la mitad y que cada uno se quede con una parte. 
Elaine acepta la decisión salomónica, mientras que Kramer suplica que la bicicleta se mantenga completa y que prefiere dársela a Elaine antes de verla partida por la mitad. Frente a la actitud de Kramer, y tal como hizo el Rey Salomón, Newman decide darle la bicicleta9.

Newman es un claro ejemplo de un Árbitro Salomónico, que se caracteriza por "partir al bebé por la mitad" u otorgar la mitad de lo solicitado, en vez de tomar una decisión basada en los hechos y las pruebas presentadas por las partes. Notablemente, la decisión de Newman ignoró la discusión más importante (si la promesa de Elaine era vinculante) para concentrarse en un criterio salomónico (quién valoraba más el bien).

En el mundo real, las decisiones salomónicas son indeseables. Éstas destruyen la confianza de las partes en el arbitraje y dañan su predictibilidad como sistema de resolución de disputas ${ }^{10}$. Recordemos que "[p]artir al bebe por la mitad simplemente acaba matándolo"11.

En un reciente arbitraje nos enteramos que dos árbitros habían decidido otorgar el 30\% del monto reclamado por la parte reconviniente. Posteriormente, y a raíz de un proceso de anulación, la parte demandada se enteró que la indemnización originalmente se iba a otorgar era del 53\%, y que el tribunal en mayoría habría rebajado dicho monto con la única finalidad, y sin razón objetiva alguna, de que el árbitro que finalmente emitió un voto disidente firme el laudo. La diferencia entre uno y otro monto era superior a los 10 millones de dólares.

Entonces, ¿con qué herramientas cuentan los árbitros para lidiar con un Árbitro Salomónico durante las deliberaciones? Veamos:

9. Esta anécdota es sacada de: C. Drahozal, "Privatizing Civil Justice: Commercial Arbitration and the Civil Justice System", Journal of Law and Public Policy, 1999-2000, pp. 578-579.

10. En el Perú, los árbitros parte bebes encuentran una "licencia para matar" a través de una mala interpretación del Art. 1332 del Código Civil Peruano, el cual los faculta a decidir en equidad en aquellos casos donde no se pueda determinar el monto del resarcimiento del daño causado a una parte.

11. J. De la JARA y R. VeGA, “"Splitting the baby kills the baby' Tres propuestas para erradicar el mito de los laudos salomónicos”, Arbitraje Comercial Internacional y Arbitraje de Inversiones, Vol. 14, 2016. 


\section{La contaminación de la confianza. \\ Los árbitros tóxicos y la deliberación arbitral en Latinoamérica}

- El presidente suele ser percibido como el mayor propulsor de laudos salomónicos para negociar una posición dentro del tribunal $^{12}$. Lo anterior es reflejo de un desconocimiento del rol del presidente, que al intentar no decepcionar a nadie termina decepcionando a todos ${ }^{13}$. Por ello, es necesario empoderar al presidente, que según la Ley de Arbitraje el presidente cuenta con voto dirimente y capacidad de decidir por sí solos. Interiorizar dicho papel ayuda a evitar decisiones salomónicas con el único fin de negociar una mayoría al interior del tribunal.

- Para evitar saltos lógicos y decisiones emocionales, es aconsejable proponer y ponerse de acuerdo en seguir un árbol de decisiones o decision tree. En esta herramienta se listan todos los puntos controvertidos, incluyendo las distintas potenciales decisiones y las discusiones a las que éstas llevarían ${ }^{14}$.

- Finalmente, es esencial que cada opinión de los árbitros esté sustentada en pruebas. Una manera respetuosa de lograr ese consenso es acordar que los árbitros deberán acudir a la siguiente reunión de deliberación habiendo redactado una breve respuesta al decision tree, con el requisito esencial de que aquella esté sustentada en los medios probatorios. Ello permitirá discutir el valor de dichas pruebas y así acercarse a una decisión mejor sustentada.

\subsection{El Árbitro Procesalosaurio}

Los procesalosaurios rondan por las escaleras del Poder Judicial. Tienen largas garras con las que amedrentan a secretarios, jueces y congresistas. Su dieta básica consiste en una porción de excepciones, con guarnición de impugnaciones y abundante salsa de formalismo ${ }^{15}$. Esta especie jurásica está caracterizada por sufrir

12. Ibídem. En una encuesta realizada a 103 practicantes del arbitraje en Latinoamérica, el $75.4 \%$ de los participantes indicó que el presidente del tribunal es el principal propulsor de laudos salomónicos.

13. U. Draetta, Behind the scenes in International Arbitration, Juris Publishing Inc., 2011, p. 93.

14. B. Meyer, "Structuring a bargaining process", en E. BERGER y M. SCHENEIDER, Inside the Black Box. How Arbitral Tribunals Operate and Reach Their Decisions, Association Suisse de 1'Arbitrage and Jurist, 2014, pp. 59-63.

15. Que quede claro: no son abogados procesalistas. Se hacen pasar como tales pero en realidad son litigantes, ex jueces u "operativos" estancados a la mitad de la cadena evolutiva y sin capacidad de adap- 
una severa miopía y un drástico astigmatismo. La primera les impide notar las diferencias entre el formalismo del proceso ordinario y la flexibilidad del arbitraje; mientras que, el segundo, evita analizar el detalle de los documentos y acceder al corazón de la controversia. Estas características presentan problemas al momento de deliberar ${ }^{16}$.

Por ejemplo, la visión formal del árbitro lo puede inclinar a deliberar únicamente si es cara-a-cara. Si bien ello es ideal, no es siempre posible ni mucho menos mandatorio ${ }^{17}$. Como ha señalado la jurisprudencia "tribunals can also deliberate exclusively by correspondece or (video-) conference calls, provided that this is also admisible under the law of the place of the arbitration"18.

La respuesta de las cortes es reflejo de la globalización y el éxito del arbitraje. Hoy en día, los tribunales son compuestos por árbitros de distintas nacionalidades y sus agendas están cada vez más copadas. A veces es ineficiente o imposible que los árbitros se reúnan presencialmente. Por ello se deben valer de los avances tecnológicos (e-mail, Skype, videoconferencia, etc) para ejercer su labor y deliberar ${ }^{19}$.

Los árbitros procesalosaurios están acostumbrados a la dinámica judicial de deliberación. Esta consiste en la sustentación de uno de los juzgadores de un dictamen escrito, para opinión de los demás (art. 138 de la Ley Orgánica del Poder Judicial Peruano).

La sustentación judicial del dictamen nace como una negativa a la deliberación, pues solo uno de los juzgadores se encarga de redactar un borrador de decisión sin haber conversado el sen-

tarse a un proceso transparente, rápido y dinámico. J. DE LA JARA, El ataque de los procesalosaurios, «https://goo.gl/eKGyY5».

16. R. WEISMAN, To judge or not to judge: retired judges as arbitrator, «http://www.americanbar.org/content/dam/aba/events/labor_law/2013/02/adr_in_labor_employmentlawcommitteemidwintermeeting/z.a uthcheckdam.pdf» (13/05/2016).

17. Sentencia del Tribunal Federal de Suiza referida al caso Sefri c. Komgrap.

18. Austria No. 16 D S.A. c. W GmbH, 26/04/2006.

19. J. Lew, en E. Berger y M. Scheneider, Inside the Black Box. How Arbitral Tribunals Operate and Reach Their Decisions, Association Suisse de l'Arbitrage and Jurist, 2014, p. 19. 
La contaminación de la confianza.

Los árbitros tóxicos y la deliberación arbitral en Latinoamérica

tido con los demás. En el arbitraje, dicha práctica es dañina, incluso si es ejecutada por el presidente del tribunal.

- Por ello, aconsejamos tomar en cuenta las siguientes medidas en caso un Árbitro Procesalosaurio forme parte del tribunal:

- Aclarar que el procedimiento de deliberación es informal. Si bien es lo ideal, no será necesario reunirse presencialmente. En cambio, los árbitros podrán sostener (video) conferencias, intercambiar correos electrónicos o cualquier otro medio de comunicación confiable. De ser posible, este acuerdo deberá ser registrado en un documento firmado por todos los árbitros.

- Fijar como objetivo un intercambio de información profuso para arribar a una decisión adecuada. Para ello resulta necesario que cada uno de los árbitros estudie y contraste los documentos, proponga qué camino se debe tomar, y luego, especialmente, se discutan los distintos puntos de vista.

\subsection{El Árbitro Justiciero}

El Árbitro Justiciero ve al proceso como una damisela en peligro. Protegido por una armadura de superioridad moral, este paladín de la justicia cree saber mejor que las partes qué es lo que les conviene. Sin embargo, en su búsqueda por un ideal de justicia arremete contra la eficiencia del arbitraje y contra la voluntad de las partes.

En su afán por hacer justicia, este árbitro es particularmente propenso a la producción y presentación de medios probatorios y enemigo de los plazos de preclusión. Cegado por su objetivo, no duda en incluir argumentos, discusiones y pretensiones que no han sido planteadas por las partes, siempre y cuándo para él sean necesarias para arribar a la Verdad (con mayúscula) ${ }^{20}$.

20. F. Spalding, "Choosing the arbitration panel" en B. Roth, R. WulfF y C. Cooper (Eds.), The ADR Practice Guide, Lawyers Cooperative Publishing, 1993-1995. 
Si bien el Árbitro Justiciero tiene buenas intenciones, no se da cuenta que su intento de ayudar a las partes puede, más bien, terminar perjudicándolas. Por ejemplo, la búsqueda incesante de la verdad puede vulnerar el derecho de defensa de las partes si se introduce un argumento nuevo en el laudo sin la correspondiente oportunidad de contrastarlo y presentar evidencia al respecto; se vulnera el derecho a obtener una decisión en un plazo razonable si se niega a cerrar instrucción para que las partes presenten más pruebas o para descubrir lo que realmente sucedió; se vulnera la confidencialidad del arbitraje y de las deliberaciones si se consulta con un tercero; se vulnera la voluntad de las partes si se incluye un asunto expresamente excluido del convenio arbitral, entre otros.

Al respecto, conviene tomar en cuenta el laudo del caso Totem Marine Tug E Barge v. North American Towing. En éste, el tribunal alegó que los demandantes "erróneamente pidieron solo los gastos como daños" 21 , por lo que reformularon el pedido del demandante otorgando un total de US\$ 157,887.63 en vez de los US\$ 74,713.63 reclamados. Frente a ello, la Corte de Apelaciones del Quinto Circuito de Estados Unidos anuló el laudo por otorgar una indemnización que duplicaba el monto solicitado por la demandante e incorporar conceptos que no habían sido reclama$\operatorname{dos}^{22}$.

A nuestro entender, los Árbitros Justicieros deben recordar que "el camino al infierno está empedrado de buenas intenciones". En ese sentido, sugerimos enfatizar lo siguiente para evitar que sus buenas intenciones lleven a las partes a un infierno de demoras.

- Recordar que la actuación de los árbitros nace y está limitada por la voluntad de las partes. Por más que su sentido de justicia les

21. "North American erroneously asked only for its returns expenses (plus some miscellaneous accounting items) in damages. The proper measure of North American's damages was the balance of charter hire due under the carter less the earnings of the vessel during that period".

22. Corte de Apelaciones del Quinto Circuito de Estados Unidos, Totem Marine Tug \& Barge, Inc. c. North American Towing, Inc., 607 F. 2d 649,651 (5 $5^{\text {th }}$ Cir. 1979). Véase, PMA Capital Inc. Co. c. Platinium Underwriters Bermuda Ltd., 400 F. Appx. 654 (3d Cir. 2010). 
La contaminación de la confianza.

Los árbitros tóxicos y la deliberación arbitral en Latinoamérica

diga que algo no está bien, como tomadores de decisiones no pueden ir más allá de lo que las partes han presentado.

- Evitar que el Árbitro Justiciero decida por sí solo cuestiones que cree podrían beneficiar a las partes. En nuestra opinión, el tribunal arbitral está facultado a consultar con las partes si tiene alguna duda, incluso sobre un punto no presentado por ellas. Lo importante es "abrir la caja negra" de la deliberación con la suficiente anticipación para que ambas partes tengan la oportunidad de pronunciarse y presentar la evidencia que consideren necesaria.

- Enfatizar que las partes han elegido acudir a un tribunal arbitral para evitar las demoras de la justicia ordinaria. Por ello, el cumplimiento del encargo del tribunal comprende la resolución célere de la controversia. En ese sentido, consideramos un acierto la nueva política implementada por la Cámara de Comercio Internacional - CCI, según la cual se penalizan demoras injustificadas en la emisión de laudos ${ }^{23}$.

\subsection{El Árbitro Fantasma}

Usted es parte de un tribunal que ha acordado reunirse para deliberar el sentido del laudo. Algunos días antes de la reunión, su co-árbitro (el señor Cancelo) llama al presidente y le informa que no podrá asistir y que se postergue la reunión. El pedido es aceptado por el presidente.

El día de la nueva reunión, el señor Cancelo vuelve a comunicarse con el presidente para solicitar, por segunda vez, una postergación de la deliberación. El presidente vuelve a acceder

Llegada la tercera fecha para la reunión, el tribunal se encuentra para deliberar pero el tiempo queda corto, teniendo que pactar una nueva reprogramación. Sorprendentemente, el señor Cancelo simplemente no asiste a la cuarta reunión.

23. Corte de Apelaciones de Beirut, Decisión No. 718/2011, 23/05/11, International Journal of Arab Arbitration, Vol. 4(2), 2012, pp. 75-77. 
Esta vez la deliberación se posterga por tres semanas para facilitar la coordinación de agendas y así, ojalá, incrementar la posibilidad de asistencia del señor Cancelo. Sin embargo, dos días antes de la nueva fecha, el señor Cancelo vuelve a pedir la reprogramación de la reunión. Lo mismo sucede en una quinta reunión.

Los hechos narrados forman parte de un caso real ${ }^{24}$ que ejemplifica el daño que puede generar un árbitro ocupado o árbitro fantasma. Éste se caracteriza por retrasar y entorpecer con sus desapariciones (excusas, falta de tiempo o falta de participación) el proceso deliberativo, poniendo en peligro la emisión del laudo dentro del plazo establecido por las partes. Su presencia no es la regla. En cambio, su aparición en una reunión se asemeja más a una actividad paranormal.

El árbitro fantasma coloca a sus co-árbitros en una encrucijada: respetar el pacto de las partes de comportarse como un tribunal colegiado y esperar hasta que aparezca para discutir el sentido del laudo o, por otro lado, tomar una decisión en su ausencia.

A nuestro entender, en esta situación los demás árbitros tendrán la potestad de aplicar el mecanismo de asimilación desarrollado doctrinal ${ }^{25}$ y jurisprudencialmente ${ }^{26}$. Dicha herramienta permite emitir un laudo válido sin la participación del árbitro fantasma, siempre que éste haya tenido las mismas oportunidades que los demás miembros del tribunal para presentar su punto de vista.

No obstante, vale recordar que el mecanismo de asimilación es una excepción al principio de colegialidad que rige la deliberación; debe ser aplicado de forma restrictiva y bajo parámetros

24. Ibídem.

25. B. BERGER, "Rights and Obligations of Arbitrators in the Deliberations", ASA Bulletin, Vol. 31(2), 2013, pp. 251-252. En el mismo sentido, J. POUdRET y S. BESSON, Comparative Law of International Arbitration, Sweet \& Maxwell Ltd., 2007, p. 656.

26. Corte Civil Suiza, Caso 4P.226/2001 del 1 de febrero del 2002. En el mismo sentido, Tribunal Federal Suizo, Caso 4p_115/2003, 16/10/2003. 
de razonabilidad. Por ello, los demás árbitros deberán evaluar primero si existe alguna situación que justifique la falta de participación del árbitro ${ }^{27}$.

En definitiva, nuestras recomendaciones para lidiar con el árbitro fantasma son las siguientes:

- Ante todo, cada árbitro debe tener las mismas oportunidades para expresar sus puntos de vista en la deliberación. Ello implica que (i) haya sido invitado a todas las reuniones, (ii) haya tenido un plazo razonable para asistir a cada una de ellas, (iii) haya recibido copia de todas las versiones del laudo, incluyendo la final, (iv) haya tenido un plazo razonable para presentar sus comentarios respecto de cada una de dichas versiones.

- En caso considere pertinente utilizar el mecanismo de asimilación, asegúrese que el árbitro fantasma no cuenta con una justificación válida para su falta de participación. Por ejemplo, en el caso FIC, el árbitro Wang Shengchang fue encarcelado. Ello, sin duda, constituye una excusa válida de su ausencia que impediría aplicar el mecanismo de asimilación ${ }^{28}$.

- Guarde una copia de todas las comunicaciones intercambiadas con el árbitro fantasma. Dependiendo de la intención del árbitro, éstas podrán ser útiles en un eventual proceso de anulación para demostrar que tuvo plena oportunidad de hacer valer su opinión pero decidió no hacerlo ${ }^{29}$.

\subsection{El Árbitro Delivery}

Imagine que el presidente del tribunal sugiere encargar al secretario arbitral la resolución y redacción de dos de las cinco pretensiones planteadas por la parte demandante. Esto es una propuesta típica de un árbitro que por falta de tiempo, irrespon-

27. S. BRocker y K. LÖF, "Chapter 8 The Proceedings" en F. MAgnusson (Ed.), International Arbitration in Sweden: A Practitioner's Guide, Wolters Kluwer Law \& Business, 2013, p. 227.

28. Alta Corte Popular de China, Provincia de Fujian, First Investment Corp. c. Fujian Mawei Shipbuilding, Tld. et al, 12/10/2007 y Suprema Corte Popular, 27/02/2008. Citado en VAN DEN BERG y A. JAN (Eds.), Yearbook Commercial Arbitration, Vol. XXXV, 2010, pp. 349-352.

29. J. WAINCYMER, N. 8, p. 1294. 
sabilidad o flojera decide involucrar al secretario arbitral. Como un establecimiento de comida rápida, el Árbitro Delivery no se dedica suficiente a "preparar" el laudo.

Imaginemos que, aliviado por la disminución de carga de trabajo, usted acepta encargar el caso al secretario arbitral. Finalmente, ¿qué es lo peor que podría pasar? Según la jurisprudencia internacional, mucho.

Recientemente, el laudo del caso $Y u k o s^{30}$ fue cuestionado en un proceso de anulación, entre otras razones, porque el secretario arbitral del caso, el profesor MARTín VALASEK, habría redactado partes sustanciales del mismo. De hecho, de acuerdo a la Federación Rusa, VALASEK habría dedicado entre un $40 \%$ a $70 \%$ más de tiempo que los demás árbitros en la redacción del laudo, lo cual constituiría un incumplimiento de éstos de ejecutar el encargo arbitral de forma personal ${ }^{31}$.

Así pues, parece prudente que los Árbitros Delivery y sus coárbitros se pregunten hasta qué punto puede el secretario participar en la deliberación o redacción del laudo arbitral.

Al respecto, el artículo 3 de la Guía de la ICCA establece que una de las funciones del secretario arbitral es la de "[d]rafting appropriate parts of the award", mientras que las Notas de la ICC ${ }^{32}$ indican que bajo ningún supuesto podrá ejercer funciones de toma de decisiones.

A nuestro entender, el secretario arbitral puede redactar directamente las secciones fácticas del laudo que no implican una función de toma de decisiones tales como antecedentes procesales, hechos del caso y posición de las partes $^{33}$. En cambio, solo

30. UNCITRAL, Yukos Universal Limited (Isle of Man) c. The Russian Federation, PCA Case No. AA 227. A la fecha de la redacción del presente artículo, el laudo de Yukos ha sido anulado en primera instancia mas no por esta razón.

31. M. Altenkirch y B. SchmeIL, "The Substantial Involvement of Arbitral Secretaries", Global Arbitration News, «https://goo.gl/15unKh».

32. Note on the Appointment, Duties and Remuneration of Administrative Secretaries. International Chamber of Commerce.

33. ICCA, Young ICCA Guide on Arbitral Secretaries. The ICCA Report No. 1, p. 15. 
La contaminación de la confianza.

Los árbitros tóxicos y la deliberación arbitral en Latinoamérica

podrá ayudar a redactar las secciones dedicadas a la decisión sobre el caso si es que el tribunal ha deliberado y ya ha determinado el sentido del punto en discusión.

El razonamiento jurídico y la resolución de la controversia es responsabilidad exclusiva de los miembros del tribunal arbitral; y es que, fue a ellos a quienes las partes escogieron para decidir la disputa. Permitir la participación del secretario arbitral en la deliberación o delegarle la responsabilidad de decidir traiciona la confianza depositada por las partes en el tribunal y podría llevar a que se plantee la anulación del laudo por una "extralimitación manifiesta de sus facultades" ${ }^{34}$ o por un "incumplimiento al pacto de las partes" ${ }^{\prime \prime 3}$.

Tomando en cuenta lo anterior, sugerimos lo siguiente para quien comparta tribunal con un Árbitro Delivery:

- Promover la actuación directa de los árbitros desde el Acta de Misión. Por ello, el secretario solo podrá asistir a las deliberaciones para ayudar con el manejo de pruebas y toma de notas; no deberá ofrecer su punto de vista ${ }^{36}$. En cuanto a la redacción del laudo, el secretario deberá limitarse a ayudar en las secciones fácticas, a menos que el tribunal ya haya tomado una decisión respecto a punto específico y requiera un primer borrador. En este último caso, sugerimos que el presidente envíe un memorándum a los demás árbitros en el que resume la posición adoptada por el tribunal y explica que el secretario colaborará en la redacción de determinadas secciones.

- En caso el presidente insista en la participación del secretario arbitral, es aconsejable que las distintas posiciones de los árbitros queden registradas en un documento o en comunicaciones. Dependiendo del caso, podría valer la pena notificar de este asunto al centro arbitral para que oriente al secretario o a las partes para que hagan valer sus derechos.

34. Véase, Art. 52.1.b. de la Convención de Washington.

35. Véase, Art. 34.2.a.iv de la Ley Modelo UNCITRAL.

36. ICCA, N. 33. 


\subsection{El Árbitro Blandengue}

El Árbitro Blandengue es incapaz de defender su posición durante las deliberaciones o tomar una decisión difícil que implique entrar en conflicto con alguno de sus co-árbitros ${ }^{37}$. Este tipo de árbitro es particularmente peligroso cuando es designado como presidente del tribunal, al no poder generar consensos, tomar una decisión firme ni utilizar su facultad dirimente cuando sus co-árbitros no lleguen a una decisión.

Un ejemplo claro de esta clase de árbitros lo podemos ver en el proceso de la Corte de Beirut narrado en la sección del árbitro fantasma ${ }^{38}$. Como recordaremos, en ese caso el señor Cancelo solicitó la postergación de la deliberación no solo en una o dos, sino en cinco oportunidades.

Así pues, en dicho caso el presidente no supo ordenar el proceso deliberativo y falló en poner mano dura dando como resultado una demora innecesaria en la emisión del laudo y una discusión insuficiente sobre su sentido.

Ahora, ¿qué medidas debemos tomar si nos topamos a un Árbitro Blandengue en una deliberación? Veamos

- Si una de las partes ha designado a un Árbitro Blandengue, el presidente deberá fomentar una discusión sana en el tribunal, poniendo especial atención a las herramientas de la psicología para incentivar la participación de los distintos miembros del grupo. Para ello, el presidente debe ser un líder inquisitivo y callado, primar el pensamiento crítico y asignar roles. Esto implica que deberá emitir su opinión al final, otorgando así mayor libertad al Árbitro Blandengue de expresar su punto de vista de manera libre y sin temor a contradecir a quien puede ver como un superior jerárquico; cambiar las reglas de juego dejando claro que el objetivo de la deliberación no es llegar a

37. F. Spalding, N. 20.

38. En la sección del "Árbitro Fantasma". El caso se puede revisar en: Corte de Apelaciones de Beirut, Decisión No. 718/2011, 23/05/2011, International Journal of Arab Arbitration, Vol. 4 (2), 2012, pp. $77-85$. 


\section{La contaminación de la confianza. \\ Los árbitros tóxicos y la deliberación arbitral en Latinoamérica}

un consenso, sino fomentar la mayor cantidad de información relevante y la libertad de expresión de distintos puntos de vista; asignar roles a los árbitros y que todos adopten el rol del abogado del diablo, asegurando así que cada co-árbitro se sienta lo suficientemente confiado para plasmar todas sus ideas y libre para pronunciarse sobre los puntos de vista de los demás ${ }^{39}$.

- En caso el presidente sea un Árbitro Blandengue, los co-árbitros serán quienes deban empoderarlo. Así, será su deber recordarle que no solo la práctica le atribuye el cargo de maestro de la orquesta, al ser quien lidera el proceso deliberativo, la misma Ley de Arbitraje le otorga un rol preponderante en tribunal, teniendo incluso el voto dirimente en caso de empate.

- En caso lo anterior falle, sugerimos actuar de manera proactiva para organizar las deliberaciones. Ello implica, por ejemplo, proponer un cronograma de reuniones para deliberar y desarrollar un decision tree, los cuales serán sometidos a aprobación de los demás miembros del tribunal.

\subsection{El Árbitro Egocéntrico}

Una vez terminada la audiencia de informe oral, los árbitros se dirigieron a la oficina del presidente del tribunal (el señor Subido) para el inicio de la deliberación. $\mathrm{O}$ al menos eso creían. Al llegar tuvieron que esperar 45 minutos a que el presidente terminara con una "llamada urgente". Cuando el señor Subido por fin llegó, se limitó a pedir una propuesta de laudo a cada uno de sus co-árbitros. "A partir de eso voy a decidir quién tiene la razón", explicó.

La anécdota anterior refleja una personalidad distinta: el Árbitro Egocéntrico. Éste se considera superior a los demás, sobreestima sus habilidades y cree ciegamente en su posición ${ }^{40}$. No suele tomar en cuenta que debe discutir la posición con sus colegas. En

39. J. De la Jara y J. Olórtegui, N. 7.

40. M. Drago y J. De La Jara, "La justicia intuitiva: consecuencias ocultas de la concesión de una medida cautelar", Sobre la tutela cautelar, Themis, 2015, p. 63. 
cambio, confía excesivamente en su análisis y en su poder de convencimiento. Éste sufre de un sesgo de egocentrismo que perjudica la deliberación, pues genera distorsiones en el procesamiento de información y barreras de comunicación que complican el intercambio de ideas ${ }^{41}$.

El caso del señor Subido es reflejo de lo anterior. El presidente tenía una visión tan distorsionada del rol que le toca cumplir, que fue capaz de encargar a sus co-árbitros la redacción de sendas opiniones para luego elegir la mejor, como si se tratara de un concurso de belleza y él fuera el juez.

Otra práctica común del Árbitro Egocéntrico es presentarse a la primera reunión de deliberación con un borrador de laudo. Como comenta BERNARDINI, ello es una falta de respeto a la posición de los demás árbitros; y es que, si uno dedica tiempo a redactar será difícil que cambie su posición y re-escriba lo ya adelantado ${ }^{42}$. Por si ello fuera poco, podría generar un peligro de conformismo y tendencia a plegarse a lo ya escrito, así como molestias por parte de quien redactó el proyecto por recibir críticas.

Asimismo, al momento de discutir su posición, el Árbitro Egocéntrico no suele escuchar a sus co-árbitros ni otorgar valor a una posición contraria a la suya. En cambio, es propenso a incurrir en un sesgo de confirmación; esto es, favorecer información que corresponde con su posición original e ignorar evidencia que apunte en el sentido contrario ${ }^{43}$.

Nótese además que el egocentrismo suele estar asociado a la necesidad de corregir a las partes o a los demás miembros del tribunal. Es así que, dependiendo de la personalidad de cada árbitro, el egocentrismo puede llevarlos a evolucionar (¿o involucionar?) en el Árbitro Super-litigante o el Árbitro Bully.

41. C. Guthrie, J. Rachlinki y A. Wistrich, "Inside the Judicial Mind”, Cornell Law Review, Vol. 87, 2001, p. 815.

42. P. Bernardini, N. 5.

43. E. Peer y E. Gamliel, "Heuristics and biases in Judicial Decisions", Court Review, No. 114, 2013, «https://goo.gl/3dcHa2». 
La contaminación de la confianza.

Los árbitros tóxicos y la deliberación arbitral en Latinoamérica

El Árbitro Superlitigante es una versión más acentuada del Árbitro Egocéntrico. Busca constantemente ser el centro de atención del proceso a través de una participación sumamente activa que reposa en sus dotes como litigante. Así, ve en las audiencias una oportunidad para lucirse. No se salva nadie, todos están a merced de sus preguntas y cuestionamientos ${ }^{44}$.

De otro lado, el Árbitro Bully es la versión más agresiva del Árbitro Egocéntrico ${ }^{45}$. Ve al arbitraje como una jungla donde reina el más fuerte. Por ello, se siente en la necesidad de comportarse como un depredador y alimentarse de abogados sin experiencia y testigos nerviosos que tengan la insolencia de cometer algún error en su presencia.

En atención a lo anterior, nuestras recomendaciones para lidiar con el Árbitro Egocéntrico, el Árbitro Super-litigante y el Árbitro Bully son las siguientes:

- Debemos lograr que el Árbitro Egocéntrico interiorice que el principio de colegialidad es la base de la deliberación. Para ello, se aconseja comenzar las discusiones lo antes posible y así tener suficiente tiempo de intercambiar puntos de vista, así como advertir a los árbitros que el tribunal no revisará ningún borrador antes de haber discutido previamente el sentido de la decisión.

- La preocupación principal con el Árbitro Super-litigante es que su hiper-actividad vicie el proceso. Por ello, se aconseja promover reglas claras antes de la audiencia, tales como tiempo de preguntas del tribunal. Asimismo, el presidente debe ejercer una labor de control indirecto y discreto (enseñándole cómo se hace a través del ejemplo o bien pidiéndole "fuera de cámaras" que deje el protagonismo a las partes).

- El objetivo principal en la deliberación con el Árbitro Bully es evitar que se sienta atacado. Para ello, en primer lugar, es vital

44. El problema con estos árbitros es que sus intervenciones pueden ser excesivas, dejando de lado la naturaleza adversarial del arbitraje y tomando un rol protagónico que, por definición, le corresponde a las partes.

45. Para ver ejemplos de esta clase de árbitros, véase, D. Richmond, "Bullies on the Bench", Louisiana Law Review, Vol. 72(2), 2012, pp. 325-327. 
no interrumpirlo durante sus desahogos de enojo; de lo contrario volverá a comenzar con el ataque. En segundo lugar, es necesario recordar que la furia está vinculado a un procesamiento de información superficial que suele llevar a argumentos efectistas y sin fondo. Por ello, el árbitro debe conocer el detalle del expediente para poder discutir con el Árbitro Bully. Finalmente, la clave está en dirigir la respuesta con empatía ("entiendo tu punto pero creo que esa conclusión puede cambiar si se toma en cuenta el hecho $X$ sustentado en la prueba $Y^{\prime \prime}$ ). En definitiva, el Árbitro Bully debe entender que quien está a su costado es otro árbitro y no su enemigo.

\subsection{El Árbitro Informante}

Durante el desarrollo de las audiencias, que duran varias horas y días, el baño se convierte en un espacio inusual de encuentro entre árbitros y litigantes. Hace algunos años, un prestigioso árbitro protagonizó una historia que refleja que éstos no son lugares tan limpios como se creería.

El árbitro en cuestión se encontraba utilizando los servicios higiénicos, dentro de un cubículo metálico. Desde su cómoda posición, escuchó cómo su co-árbitro (el señor Topo) discutía con la parte que lo designó el sentir del tribunal y cuáles serían las mejores preguntas para desacreditar la posición de su contraparte. Naturalmente, el árbitro informó lo que había escuchado al presidente, quien aconsejó esperar a ver si el señor Topo formulaba las preguntas que habían conversado. Finalmente, el señor Topo realizó las mismas preguntas que había discutido con el abogado de la parte que lo había designado.

Esta anécdota refleja el típico caso de un Árbitro Informante, caracterizado por comunicar a una de las partes el feeling de los demás árbitros, dar consejos de cómo mejorar su caso o recibir propuestas de cómo persuadir al tribunal. 
Al respecto conviene recordar aún reciente "escándalo Sekolec". En julio del 2015, salieron a la luz audios que comprometían a Jernej Sekolec, ex secretario de la UNCITRAL y árbitro en una disputa limítrofe entre Croacia y Eslovenia. En éstos existía evidencia de una reunión entre Sekolec y Simona Drenik, representante de Eslovenia, en la que le habría comentado a la funcionaria pública acerca del posible resultado del caso y de sus esfuerzos para persuadir a los demás miembros del tribunal de que favorezcan a Eslovenia ${ }^{46}$.

Como podemos observar, el árbitro informante vulnera el secreto de las deliberaciones, principio básico del sistema de toma de decisiones ${ }^{47}, \mathrm{y}$, peor aún, otorga un beneficio indebido a una de las partes, afectando el debido proceso y el trato igualitario, lo que eventualmente podría llevar a una anulación del laudo arbitral.

¿Qué podemos hacer si debemos deliberar con quien sospechamos podría ser un Árbitro Informante? Estas son algunas recomendaciones:

- Si antes de que se cierre instrucción toma conocimiento y tiene evidencia de que el tribunal está contaminado con un Árbitro Informante, tiene el deber de, primero, discutirlo con el tribunal, y segundo, comunicarlo a las partes, a fin de que la parte agraviada pueda recusar al árbitro en cuestión, se nombre un árbitro sustituto y se pueda continuar con el arbitraje ${ }^{48}$.

- En caso no se tenga pruebas fehacientes que acrediten la filtración de información, lo recomendable es que esto no se comunique a las partes. En este caso, los árbitros no parcializados deberán limitarse a analizar con mayor cautela los argumentos que el árbitro informante presenta ante ellos durante las deliberaciones. Mejor aún, el tribunal debería re-

46. A. Ross, "Poisoned waters': Croatia's stance on the Sekolec Scandal”, Global Arbitration Review, Vol. 10(4).

47. Ad Hoc UNCITRAL, Himpurna California Energy Ltd. c. Republic of Indonesia, 26/09/1999.

48. Según la Ley de Arbitraje Peruana no es posible recusar a un árbitro luego del cierre de instrucción. Sin embargo, sí sería posible impulsar su renuncia. 
alizar una lista con los asuntos controvertidos o hechos que deberían recibir más atención de las partes y, con el acuerdo de éstas, compartirla. Esto permitiría eliminar la ventaja irregular de una de las partes en la recepción de información.

- Las reuniones de deliberación deben registrarse. Por ejemplo, se puede elaborar un memorándum que resuma las conclusiones arribadas y los puntos por discutir. Ello facilita la detección y acreditación de una fuga de información dentro del tribunal arbitral.

\subsection{El Árbitro Kamikaze}

La deliberación para la emisión del laudo es la última fase de la tarea del tribunal. Luego de aproximadamente año y medio en el que ha revisado memoriales de demanda y contestación, escuchado a los abogados de las partes, sus testigos, expertos legales y peritos-el final del proceso está cerca.

Imagine que el tribunal que usted conforma existe una mayoría (el presidente y usted) que ha expresado que las pretensiones de la demandante deben ser declaradas fundadas. Su co-árbitro, designado por la demandada y claramente parcializado, está en desacuerdo. Y enfrentado a la mayoría en el tribunal, decide renunciar con la finalidad de dilatar la emisión del laudo.

Imaginemos otro escenario. Esta vez, su co-árbitro no renuncia, sino que comunica a las partes que no va a firmar el laudo porque existen una serie de "irregularidades". No precisa a qué se refiere ni adjunta prueba alguna. Su único objetivo ha sido "sembrar" una causal de nulidad en favor de la parte que lo designó.

Estas son algunas de las tácticas de guerra utilizadas por el Árbitro Kamikaze, un sujeto que intenta destruir el laudo arbitral inmolándose durante su elaboración o dejando "bombas" para que este sea anulado posteriormente. 
La contaminación de la confianza.

Los árbitros tóxicos y la deliberación arbitral en Latinoamérica

Ahora, ¿los árbitros pueden continuar con el arbitraje frente a una renuncia súbita o se debe esperar a la designación de un sustituto? Actualmente no existe consenso y se continúa discutiendo, a nivel doctrinario y de cortes, si se requiere un acuerdo expreso de las partes para continuar con el proceso ${ }^{49-50}$.

En nuestra opinión, no es posible determinar de manera general si se debe esperar o no a la nominación de un árbitro sustituto. En cambio, los árbitros restantes deberán realizar un análisis costo-beneficio de cada caso concreto, tomando en consideración los criterios enumerados al final de esta sección.

Sin perjuicio de lo anterior, consideramos que la intención de las partes de acudir al arbitraje es una referencia implícita a que desean resolver sus controversias de manera célere y transparente. Por ello, los árbitros deben prestar especial atención a la demora del proceso y a la posible responsabilidad de la parte que designó al Árbitro Kamikaze. En nuestra opinión, dicha clase de designación podría reflejar una voluntad contaminada, siendo deseable que quien realizó la designación asuma las consecuencias de su decisión.

En cualquier caso, el propio BoRN ${ }^{51}$ reconoce que el artículo 12.2 del Reglamento de Arbitraje de la LCIA permitiría continuar con el arbitraje sin reemplazar al Árbitro Kamikaze. Notablemente, el artículo 33 del Reglamento del Centro de Arbitraje de la Cámara de Comercio de Lima es bastante similar, por lo que los árbitros restantes podrían continuar con la emisión del laudo amparándose en dicha provisión, incluso bajo la posición de quienes exigen un acuerdo expreso.

En cuanto a la "siembra" de artillería para la anulación del laudo, consideramos que ello constituye una excepción al secreto

49. Para ver la posición a favor de continuar con el proceso, véase, A. REDFERn y M. HunTER, Redfern and Hunter on International Arbitration, 6th Ed., Oxford University Press, 2015, p. 4155.

50. Para revisar la posición contraria, véase, J. Poudret y S. BESSON, N. 25, p. 658. Sentencia, 30/04/1991, DTF 117.

51. G. BoRn, International Commercial Arbitration, 2nd Ed., Wolters Kluwer Law \& Business, 2014, p. 1958. 
de las deliberaciones. El secreto de las deliberaciones está pensado para proteger la independencia del tribunal e impedir que las partes tomen ventaja de la información discutida; los árbitros restantes no pueden ser cómplices del atentado de un árbitro tóxico ${ }^{52}$. Por ello, los árbitros restantes estarán facultados a "abrir la caja negra" de la deliberación y proteger el laudo de la manera que consideren más adecuada, lo cual podría implicar, adjuntar correos electrónicos o memorándums de reuniones que demuestren que el árbitro sí tuvo oportunidad de participar en la deliberación, promover que dicho asunto sea analizado por la autoridad administrativa competente ${ }^{53}$ y eventualmente declarar como testigos en el proceso de anulación.

En atención a lo anterior, sugerimos tomar en cuenta estas recomendaciones para deliberar con un Árbitro Kamikaze:

- Si un árbitro renuncia súbitamente con el único propósito de perjudicar el proceso, los árbitros restantes deberán realizar un análisis costo-beneficio para decidir si deben esperar al nombramiento de un sustituto o seguir con el proceso. Dicho análisis deberá tomar en consideración (i) el estado del proceso; (ii) su dificultad; (iii) el daño generado por el árbitro renunciante; (iv) si el pacto de las partes, el reglamento aplicable o la lex arbitri contienen una regla que les permite continuar con el proceso y, especialmente; (v) buscando que la decisión sea lo más beneficiosa para las partes.

- Si existe la mínima sospecha de que un Árbitro Kamikaze forma parte del tribunal, será especialmente relevante promover mecanismos que permitan registrar las actuaciones del tribunal, tales como memorándums de reuniones firmados por los árbitros o correos electrónicos enviados por el presidente o el secretario resumiendo cada encuentro. Estos podrían ser útiles en un eventual proceso de anulación.

52. J. WAINCYMER, N. 8, pp. 1298-1299.

53. Consejo Superior de Arbitraje en los casos administrados bajo el Reglamento de la Cámara de Comercio de Lima. Al respecto, véase, Art. 12.c del Estatuto del Centro. 
La contaminación de la confianza.

Los árbitros tóxicos y la deliberación arbitral en Latinoamérica

- En nuestra opinión, la "siembra" de una causal de anulación activa la obligación de los árbitros restantes de proteger el laudo. Por ello, consideramos que deben considerar seriamente romper el secreto de las deliberaciones y promover mecanismos que mitiguen la acusación del Árbitro Kamikaze, tales como adjuntar registros de la deliberación o solicitar una opinión a la entidad administrativa competente.

\subsection{Los Árbitros Gangsters}

"A lawyer with his briefcase can steal more than a hundred men with guns". Esta frase compartida por el capo de la mafia Vito Corleone describe el perfil de los Árbitros Gangster. Veamos un ejemplo.

Llegado el momento de laudar, el presidente del tribunal anunció a los árbitros A y $\mathrm{F}$ que él se encargaría de redactar el primer proyecto de laudo. Varias semanas después, el presidente circuló por correo electrónico dos versiones del proyecto, sin otorgar tiempo suficiente ni recibir comentarios entre uno y otro envío. $\mathrm{O}$ al menos eso es lo que creía el árbitro $\mathrm{F}$.

En realidad, la verdadera "deliberación" se llevaba a cabo de manera privada entre el presidente y el árbitro A. Estas reuniones se realizaron en repetidas ocasiones, sin convocar ni notificar posteriormente al árbitro $\mathrm{F}$.

El caso anterior refleja la actuación de dos Árbitros Gangsters, caracterizados por juntarse para disfrazar al laudo de validez, cuando en realidad es una decisión hecha a la medida de la parte que "contrató sus servicios".

En el caso anterior, el árbitro $\mathrm{F}$ fue excluido de las deliberaciones. Algo peor sucedió en el arbitraje Puma c. Estudio 200054, en el que el presidente " $\mathrm{R}$ " y el coárbitro " $\mathrm{T}$ " aprovecharon que el coár-

54. Audiencia Provincial de Madrid (Sección Vigesimosegunda), Puma AG Rudolf Dassler Sport/Estudio, 2000, Caso No. 200/2011, 10/06/2011. 
bitro "I" se encontraba fuera de Madrid para reunirse y modificar lo que se había acordado previamente de manera colegiada ${ }^{55-56}$.

Así, el modus operandi de los Árbitros Gangster está encaminado a simular una discusión transparente, cuando en realidad solo quieren beneficiar a una de las partes. Los casos revisados coinciden en la exclusión del tercer árbitro y el consecuente incumplimiento del principio de colegialidad, ya sea porque dos árbitros se reunieron de manera privada sin invitar ni notificar sus conclusiones al tercero, porque no le dieron suficiente tiempo para emitir sus comentarios o porque simplemente no le avisaron antes de comunicar la decisión a las partes.

Frente a ello, conviene recordar que la exclusión del árbitro no es subsanada por su facultad de emitir un voto disidente. En realidad, dichos votos no forman parte del laudo arbitral ${ }^{57}$. Más importante aún, y como bien se ha señalado en los casos Goller ${ }^{58}$ y $F C I^{59}$, un laudo sin deliberación simplemente no es un laudo, por lo que no debe ser tomado en cuenta.

Asimismo, consideramos que la actuación de los Árbitros Gangster faculta al tercer árbitro a romper el secreto de las deliberaciones para informar a las partes de las irregularidades que se han cometido, ya sea en una comunicación durante el arbitraje o como testigo en un proceso de anulación ${ }^{60}$.

En base a lo indicado, sugerimos tener en cuenta las siguientes medidas en caso tenga la sospecha que está deliberando con Árbitros Gangster:

- Promueva un acuerdo entre los árbitros respecto a un cronograma de reuniones para la formación del laudo. Esto le dará

55. Si bien luego el presidente envió al coárbitro "I" esta última versión del laudo, ello en realidad fue solo una formalidad: sólo tres minutos después el secretario arbitral envió a las partes el "laudo final".

56. Véase también, Corte Suprema Popular de la República Popular de China, Guangying Garment c. Eurasia, 2008; David Goller c. Liberty Mutual Insurance Co, 1990, párr. 541.

57. G. BorN, N. 51, p. 3053.

58. Véase, David Goller v. Liberty Mutual Insurance Co., 1990, párr. 541.

59. Alta Corte Popular de China, N. 28.

60. J. WAINCYMER, N. 18, pp. 1298-1299. 
La contaminación de la confianza.

Los árbitros tóxicos y la deliberación arbitral en Latinoamérica

mayor previsibilidad al procedimiento de deliberación, elevará los costos de esfuerzo para excluirlo y le permitirá rastrear los cambios en los proyectos entre una y otra reunión.

- Genere pruebas de que está buscando participar en la deliberación del tribunal. Envíe correos electrónicos a sus co-árbitros. Si no son respondidos considere enviar comunicaciones formales, copiando al centro de arbitraje que administra la controversia. Estas pruebas podrían servir en un eventual proceso de anulación para acreditar que usted fue excluido por el tribunal.

- Si está seguro que está siendo excluido de la formación del laudo, considere romper la confidencialidad de las deliberaciones. Dependiendo del caso concreto, usted podrá optar por (i) enviar una comunicación formal a los co-árbitros denunciando su exclusión; (ii) comunicar a las partes y al centro de arbitraje que administra la controversia que se está violando el principio de colegialidad, o (iii) concentrarse en generar pruebas de dicha violación en el entendido que los Árbitros Gangster no cambiarán su posición y que podría resultar más conveniente apuntar a la anulación del laudo. En cualquiera de los casos, no deje a las partes a la deriva del proceso de anulación: no tenga miedo en expresar su opinión en un voto disidente, considere detenidamente la posibilidad de adjuntar registros de la falta de deliberación o de los cambios unilaterales perpetrados por los árbitros restantes y preséntese como testigo en el proceso judicial.

\section{Siete Consejos PARA PROMOVER UNA DELIBERACIÓN SANA}

Como comentamos al inicio, en paralelo a este trabajo hemos realizado una encuesta de percepción que ha sido respondida por 158 practicantes del arbitraje, de 17 países de Latinoamérica y con un promedio de experiencia de 10.2 años. 
Los resultados muestran que los árbitros encamisetados (Informante, Kamikaze y Gangster) generan más daño a las partes y mayor dificultad en la deliberación:

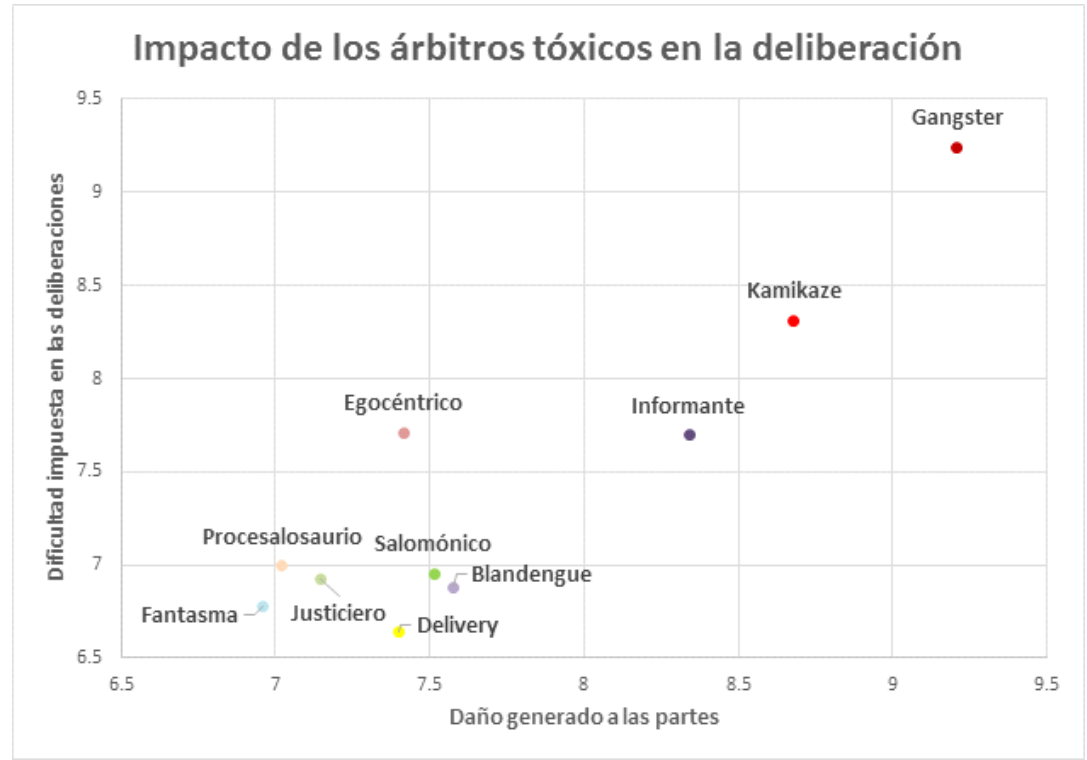

Notablemente, el $77.4 \%$ de los encuestados considera que la presencia de un árbitro tóxico puede ser contrarrestada por un buen presidente. Por ello, conviene recordar que el presidente es el director de la orquesta ${ }^{61}$ y como tal es el encargado de (i) fijar la fecha para iniciar la deliberación; (ii) organizar el procedimiento; (iii) promover la participación de sus co-árbitros y (iv) garantizar que todos los puntos controvertidos sean discutidos ${ }^{62}$.

Para cumplir dichas tareas, y con el objetivo de lograr un intercambio eficiente de información entre los miembros del tribunal, recomendamos promover las siguientes acciones:

i. Reserve tiempo para conocer a sus co-árbitros. La cantidad de información que se comparta en la deliberación depende de la confianza que existe entre los árbitros. Por ello, el presidente

61. Ibídem.

62. J. Alonso, "Deliberation and drafting awards in international arbitration" en M. Fernandez-BallesTERos y D. ARIAS (Eds.), Liber Amicorum Bernardo Cremades, La Ley, 2010, p. 134. 
La contaminación de la confianza.

Los árbitros tóxicos y la deliberación arbitral en Latinoamérica

debe intentar conocer a sus co-árbitros apenas tenga la oportunidad.

ii. Inicie la deliberación cuanto antes. En la medida de lo posible, la deliberación deberá iniciar -aunque de forma gradual- a partir de la recepción de los escritos de ambas partes. Al respecto, RIVKIN recomienda a los árbitros viajar y encontrarse para la conferencia procedimental y así poder llevar a cabo una discusión preliminar, cuidándose de protegerla con un disclaimer ("me gustaría escuchar más sobre esto en la audiencia porque tal vez podría cambiar mi posición"; "según lo que he visto hasta ahora, mi impresión es que ..." ${ }^{63}$.

iii. Proponga reunirse un día antes de las audiencias (Reed Retreat). Es recomendable que los árbitros se reúnan un día antes de las audiencias para discutir sobre el caso y cómo debería proceder aquella ${ }^{64}$. Esto permite focalizar la atención de los árbitros y transparenta las posiciones preliminares que mantienen.

iv. Registre las deliberaciones. Según nuestra encuesta, los árbitros registran en promedio solo 1.82 de cada 10 deliberaciones. Es más, el 53.8\% de los encuestados respondió que no habían registrado ninguna de las deliberaciones. Como hemos visto, el récord es vital para protegerse frente a las prácticas tóxicas. Por ello, sugerimos encargar al secretario que registre las incidencias de las deliberaciones.

v. Reserve tiempo para deliberar durante las pausas y luego de la audiencia. Durante cada día de audiencia suelen haber aproximadamente cuatro pausas por coffee break y una por almuerzo. Los árbitros deberían utilizar estas pausas para discutir de la evidencia que acaban de presenciar y profundizar en el entendimiento del caso. Más importante aún, los árbitros nunca deberían fijar el vuelo de regreso para el mismo día que terminan las audiencias. En cambio, es preferible que reserven tiempo para deliberar apenas terminen las audiencias, pues en ese momento la evidencia aún está fresca en la memoria.

63. D. Rivkin, en E. Berger y M. Scheneider, Inside the Black Box. How Arbitral Tribunals Operate and Reach Their Decisions, Association Suisse de l'Arbitrage and Jurist, 2014, p. 22.

64. Ibídem. 
vi. Fomente el intercambio de información. Para ello, el presidente deberá ser un líder inquisitivo y callado, primar el pensamiento crítico y promover la asunción de distintas posiciones. Así, es recomendable que el Presidente promueva la presentación de las ideas de sus co-árbitros antes de presentar su posición, incentive la discusión incluso cuando hay una posición mayoritaria y asuma el rol del abogado del dia$b l o^{65}$. El presidente debe ser quien estructure el proceso de deliberación.

vii. No demore en escribir. Es importante que las ideas se plasmen lo más pronto posible. Por un lado, de esta forma, las ideas que surgieron en la discusión con los demás árbitros no se pierden; por otro lado, así el laudo se termina de redactar con mayor antelación, lo cual permitirá que las partes tengan con mayor celeridad una solución a su controversia. Si se dividió la elaboración del laudo entre todos los árbitros, lo mejor es que el presidente dé un ajuste final de estilo. No es recomendable demorar la emisión de un laudo solo por una corrección de estilo.

\section{Palabras finales}

Los árbitros tóxicos traicionan la voluntad de las partes con su irresponsabilidad, falta de experiencia y desidia. Por su lado, los árbitros encamisetados corrompen el proceso, vendiendo decisiones al mejor postor. Así, los árbitros tóxicos contaminan el sistema arbitral.

Es necesario luchar activamente contra las prácticas tóxicas del arbitraje. Ponerse una máscara de gas y pretender que estamos protegidos es irresponsable. Una posición pasiva permite que el virus se siga expandiendo y genere más adeptos.

Por ello, requerimos internalizar que el miedo también corrompe el sistema. No hay que tener miedo de negarnos al pedido

65. J. De la Jara y J. Olórtegui, N. 7. 
de un cliente de designar a un árbitro tóxico; no hay que tener miedo de denunciar una irregularidad; ni hay que tener miedo de generar y adjuntar pruebas de dichas irregularidades para no dejar a las partes a la deriva del proceso de anulación. Exponga en seminarios. Escriba. Discuta. No tenga miedo de alzar la voz y denunciar las prácticas tóxicas. Después de todo, como decía el juez Brandeis, "la luz del sol es el mejor de los desinfectantes". 